\title{
IT'S SHOW TIME! ALL THAT JAZZ Y EL COREÓGRAFO COMO PERSONAJE CINEMATOGRÁFICO
}

\section{Begoña Olabarria Smith}

Investigadora Independiente

\section{Resumen}

La danza ha sido desde los orígenes del cinematógrafo un atractivo ingrediente para el séptimo arte. No obstante, las películas que presentan a sus creadores resultan la excepción. De entre estas excepciones caben destacar películas como Isadora (Karel Reisz, 1968) o Nijinsky (Herbert Ross, 1980), donde se impone una representación idealizada del genio creador que se enfrenta a los convencionalismos que le rodean. Frente a esta imagen poetizada del coreógrafo, la película All that Jazz (Bob Fosse, 1979), cercana temporalmente a las dos mencionadas, muestra un personaje absolutamente humano en sus imperfecciones. Por esta razón, la obra más personal de Fosse se convierte en un buen punto de origen para el estudio de la representación del coreógrafo en el cine y para entender la forma en la que la gran pantalla ha representado la danza y a sus creadores.

Palabras clave: DANZA; COREÓGRAFO; CINE; MUSICAL

\section{IT'S SHOW TIME! ALL THAT JAZZ AND THE CHOREOGRAPHER AS A MOVIE CHARACTER}

\begin{abstract}
Dance has been a common ingredient in films ever since the creation of cinema; nonetheless, films focussing on its makers are but an exception. Some of these exceptions would be films such as Isadora (Karen Reisz, 1968) or Nijinsky (Herbert Ross, 1980), where it is normal to see portrayed an ideal representation of the creative genius that faces the mediocrity surrounding him. Opposing these poetical images of the choreographer, All that Jazz (Bob Fosse, 1979), released around the same time as the mentioned ones, shows an absolutely human character in his imperfections. That's why Fosse's most personal work becomes a great starting point for the study of the representation of the choreographer in cinema and to understand the way dance and its creators has been represented in the movies.
\end{abstract}

Key Words: DANCE; CHOREOGRAPHER; CINEMA; MUSICAL

01abarria Smith, Begoña. 2019. "It's show time! All that Jazz y el coreógrafo como personaje cinematográfico“. AusArt 7 (2): 129-136. D0I: 10.1387 /ausart.21133

\section{AUSART}


Desde los orígenes del cine la danza ha sido un elemento recurrente: a veces como pieza fundamental de una película y otras como simple accesorio ornamental o narrativo. A pesar de esto, el autor de piezas de danza no ha provocado tanto interés en el medio cinematográfico por ello al ver una película como All That Jazz (Bob Fosse, 1979), donde el protagonismo no solo recae sobre un coreógrafo sino que el propio autor de la película fue un coreógrafo, merece la pena comenzar una reflexión sobre la forma de representación del coreógrafo en el cine.

\section{REPRESENTACIÓN DEL COREÓGRAFO EN EL CINE: MARCO CONTEXTUAL}

A pesar de que el interés del séptimo arte por la figura del coreógrafo ha sido escasa no ha sido inexistente y su presencia se encuentra ya desde el cine primitivo en el que la danza fue un elemento esencial tanto en películas que documentaban formas coreográficas preexistentes como en aquellas primeras películas del cine de atracciones, es decir, aquel cuyo objetivo era fascinar al espectador (Minguet 2013), en las que la danza proporcionaba opulencia a la pantalla y se convertía en protagonista. En uno de estos films de atracciones se encuentra probablemente la primera representación del coreógrafo como tal; se trata de Le reve du maitre de ballet (Georges Méliès, 1903) en la que se muestra un hombre obsesionado con su trabajo al que su criada ha de enviar a la cama donde el maestro termina soñando con más danza.

A pesar de la existencia de este prematuro ejemplo, como se ha mencionado, la profesión de coreógrafo no ha inspirado muchos personajes en el cine occidental, y se puede observar cómo, por regla general, su aparición se limita a cuatro tipos de películas: a los musicales de entre bastidores, a las fantasías de logro, a las películas centradas en la profesión de danza y a las biografías que narran la historia de un bailarín o coreógrafo.

En primer lugar, los musicales cuya trama está ambientada en un contexto teatral o cinematográfico y que giran en torno a la producción de un espectáculo, es decir, los llamados musicales de entre bastidores, fueron de los primeros en los que apareció la figura del creador de danza. Un ejemplo de este tipo de películas se encuentra en Shall We Dance? (Mark Sandrich, 1937) en la que Fred Astaire interpreta a un bailarín-coreógrafo frustrado por no poder crear un ballet basado no solo en la técnica del ballet clásico sino también en la danza 
vernácula estadounidense. A pesar de que sí se habla de que es un creador, lo cierto es que no se ahonda mucho en esta faceta del personaje posiblemente porque, siguiendo las convenciones del género, al buscar una apariencia de espontaneidad se produce un "encubrimiento de la coreografía y los ensayos" (Feuer 1982, 20).

A pesar de que el proceso de ensayo y de aprendizaje adquiere vital importancia en películas de danza donde un intérprete ha de enfrentarse a una prueba para entrar en una escuela o en una compañía o como las denomina Angela McRobbie (1997) "fantasías de logro", lo cierto es que también en filmes como Dirty Dancing (Emile Ardolino, 1987) o Save the Last Dance (Thomas Carter, 2001) la labor de intérprete parece superponerse al trabajo de creador de danza, que está claro que tanto Johny Castle en la primera como Sara Johnson, en la segunda, llevan a cabo. Tampoco en películas de este tipo en las que la labor del coreógrafo recae en un docente, como sucede en Billy Eliot (Stephen Daldry, 2000), se le da demasiada importancia.

Las cosas parecen cambiar al analizar aquellas películas donde la trama se centra en la profesión de la danza. En estas se puede ver una clara división entre las películas realizadas antes de los setenta y las posteriores. Las clásicas, tales como The unfinished dance (Henry Koster, 1947) o The Red Shoes (Michael Powell \& Emeric Pressburger, 1950), a pesar de hacer mención a la figura del coreógrafo (sobre todo en el caso de la segunda en la que el papel es interpretado por Léonide Massine, famoso por su trabajo con la compañía Les Ballets Russes de Sergei Diágilev), lo cierto es que el protagonismo narrativo recae sobre los directores de la compañía. En películas de este tipo más actuales como Black Swan (Darren Aronofsky, 2010) el coreógrafo adquiere importancia. A pesar de esta pequeña diferencia, lo cierto es que en ninguna de ellas se muestra verdaderamente el trabajo del coreógrafo. No obstante en ambos casos tanto la figura del coreógrafo como la del director de la compañía coinciden en exigir la entrega absoluta de sus intérpretes, continuando con la idea de poner en evidencia la labor del bailarín.

La danza también goza de absoluto protagonismo en películas biográficas de bailarines o coreógrafos y en el caso de estas últimas, resulta evidente que el creador de danza y su labor adquieren el protagonismo que se le niega en otros casos. Películas que entran en esta categoría son Isadora (Karel Reisz, 1968) o La danseuse (Stéphanie Di Giusto, 2016). Ambas cuentan la historia de dos revolucionarias de la danza que vivieron a principios del siglo veinte: Isadora Duncan en el caso de la primera y Loïe Fuller, en el caso de la 
segunda. En ellas, la figura de la coreógrafa se idealiza igual que en otras películas "sobre músicos, pintores y escritores que se comportan como auténticos héroes en su intento de abrir el universo a los demás hombres" (Sánchez-Escalonilla, 2002: 49). En esta categoría se encontraría también la reciente Yuli (Iciar Bollaín, 2018) que se desvía del típico planteamiento de "bailarín que lucha por bailar" dado que cuenta la historia de un niño que a pesar de no querer bailar llega a ser uno de los mejores bailarines y coreógrafos del mundo.

Mención aparte merece A Chorus Line (Richard Attenborough, 1985), basado en el musical de Broadway creado y dirigido, así como coreografiado, por Michael Bennet. Aquí la figura del coreógrafo recibe mucha más atención que en el resto de musicales de entre bastidores; no obstante, una vez más los verdaderos protagonistas son los bailarines, llegándose a insinuar que alguien se hace coreógrafo porque no baila lo suficientemente bien.

\section{ELLOS CREAN: YO HABLO TÚ BAILAS}

Este breve repaso de la aparición del coreógrafo en el séptimo arte constata el escaso protagonismo que ha tenido esta figura en el cine. Además, su análisis da una idea de las características que presenta, por regla general, el personaje del coreógrafo en el cine.

La primera de ellas es que el papel de creador de danza recae mayoritariamente en personajes masculinos, sobre todo en los casos en los que existe una clara diferencia entre coreógrafos e intérpretes como sucede en Black Swan o The Red Shoes. Cuando el papel de coreógrafo recae sobre una mujer suele tratarse de profesoras que crean a la vez piezas coreográficas como sucede con el personaje de Miss Berg en Fame (Alan Parker, 1980) o de intérpretes que crean sus propias piezas como Alex la protagonista de Flash Dance (Adrian Line, 1983); en ambos ejemplos esta labor creadora pasa desapercibida. En los casos excepcionales de La danseuse (en la que el propio título refleja que la labor de intérprete resulta más importante que su labor como creadora e investigadora) e Isadora, la película parece centrarse en su excepcionalidad como mujeres que rompieron moldes. No obstante, resulta interesante señalar dos verdaderas excepciones bastante recientes: por un lado, la película Frances Ha (Noah Baumbach, 2012), en el que la coreografía, como en el caso de $A$ Chorus Line, se presenta como una segunda opción en los deseos de la protagonista que inicialmente quiere ser intérprete; y el de 
Step Up (Anne Fletcher, 2006), en el que no solo la creación de piezas coreográficas recae sobre una mujer sino que, desde el principio de la película, esto se presenta como el deseo que la protagonista ha de cumplir reflejándose, asimismo, el proceso creativo que se lleva a cabo.

Otra característica que se puede observar en la representación del coreógrafo y del intérprete-creador es que se hace hincapié en la "dimensión heroica del artista", ya que por regla general estos personajes suelen tener que vencer numerosos obstáculos, tanto físicos como sociales, para alzarse por encima de una existencia triste.

Además, en muchas ocasiones el coreógrafo suele convertirse en la voz que recuerda que la danza exige renunciar a muchas cosas, ya que como se dice en The Red Shoes: "El bailarín que depende del amor humano nunca será un gran bailarín".

\section{IT'S SHOW TIME: EL COREÓGRAFO SEGÚN BOB FOSSE}

All that Jazz es una película extraordinaria en muchos aspectos: por un lado rompe con todas las convenciones del género presentando "un nuevo concepto de musical" (Rodero 1980, 45) en el que se olvida la glorificación del mundo del espectáculo y la felicidad que suelen caracterizar al género para mostrar una imagen cínica de la vida y de la farándula con un final en el que el protagonista muere. Se suele decir que en las películas de Bob Fosse "el bailarín se convierte en filósofo, en alguien que quiere comunicar (...) ideas y reflexiones en torno a su arte" (Armada 2001, 93). Debido al "estilo sensual y sórdido de Fosse" (179) esta película ha sido descrita como un "musical post-clásico" (Moreno Candeal 2008, 343). Pero sobre todo, su excepcionalidad reside en que es la única película dirigida (y en parte escrita) por un director que es a la vez coreógrafo y cuyo protagonista es un coreógrafo. Asimismo, las similitudes entre Joe Gideon, personaje protagonista, y el director son tan numerosas que en muchas ocasiones se la considera una película autobiográfica. De hecho, Fosse murió de una complicación cardiaca siete años después del estreno de este film y numerosos medios hablaron de All That Jazz como de "la historia de su propia muerte" (Ramos 1987, 37). No obstante, a pesar de admitir cierta identificación con el personaje protagonista, en la presentación de la película en el festival de Cannes afirmó que "cualquier director se 
identifica con todos sus personajes y las aventuras en las que se embarca" (Sheehan, en Fosse 2017).

Pero más allá de las particularidades del autor la pregunta que se ha de responder ahora es ¿cómo se representa al coreógrafo en la película All That Jazz?

Bob Fosse deja bien claro cómo es Joe Gideon en los primeros minutos de la película intercalando la gran escena de la audición con la de la conversación que este mantiene con Angelique, el ángel de la muerte. Joe Gideon es, en primer lugar, un mentiroso dado que en su interacción con una bailarina que miente en su CV él le quita importancia a este hecho admitiendo que él "miente todo el rato" y sobre todo miente a las mujeres con las que está (su mujer, su novia y su amante), tal y como confiesa a Angelique. También es un narcisista y busca que lo adulen, como demuestra al hacer que una bailarina que está realizando la audición le diga lo buen coreógrafo y director que es. Es una persona que "piensa que está vivo solo cuando trabaja", según palabras de Roy Schneider (2017), actor que encarnó el papel de Gideon. Es decir, prioriza su trabajo al resto de los elementos de su vida o en palabras del propio Gideon: "la vida es estar en el alambre, lo demás es esperar". El colocar el éxito laboral por encima de su vida personal lo lleva a fracasar como padre y a no mantener las promesas que hace a su hija. A pesar de esto en la escena en la que baila con ella muestra cómo es capaz de demostrarle su afecto. Es decir, su vida gira de tal manera alrededor de la danza que como mejor expresa su amor es bailando.

Por tanto, en esta película nos encontramos ante un coreógrafo que comparte muchas de las características anteriormente mencionadas: un hombre obsesionado con su trabajo que si se observa de cerca no carece completamente de cierta dimensión heroica. Esto se puede apreciar en la misma escena de la audición en la que muestra una sorprendente gentileza para con los bailarines. También y, sobre todo, en la escena de Airerotica, que se convierte en una lucha entre la visión creativa de Gideon y los valores comerciales defendidos por los productores.

Otro hecho curioso es que Fosse no muestra ningún respeto por la figura del coreógrafo y se ríe de él al presentar a Gideon en la escena final como: "un artista mediocre, no demasiado humanitario y amigo de nadie" según palabras del MC Ben Vereen. Sin embargo sí muestra cariño y respeto hacia los bailarines, como demuestra la ya mencionada escena de la audición tanto 
en la planificación como en el trato de Gideon hacia los bailarines. Incluso el respeto que niega a las mujeres con las que está sí se lo da a las bailarinas, algo que se ve en su relación con Victoria, que no parece entusiasmarle, pero de la que es capaz de sacar todo su potencial en la sala de ensayo. De igual manera, aunque dice fracasar como padre, es también en una sala de ensayo y bailando con su hija el momento de la película en la que se muestra el lado más humano del personaje.

\section{A MODO DE CONCLUSIÓN}

Como se ha visto, en All That Jazz se presenta un coreógrafo mentiroso, narcisista que no trata bien a las mujeres de las que se rodea y que pone por encima de todo a su trabajo; es decir, no resulta muy diferente de otros coreógrafos cinematográficos. La verdadera diferencia del trabajo de Fosse es la profundidad que adquiere el personaje de Gideon. Por todo esto este personaje ha influido en la visión que se tiene del coreógrafo y podemos encontrar trazos de él en la forma en la que Hollywood (y también diferentes series de televisión) representan a los creadores de danza. De esta manera, se puede ver ciertas reminiscencias de Joe Gideon en el Zach de A Chorus Line, en el Thomas Leroy de Black Swan o en las series televisivas Flesh and Bones o Smash. De hecho, podría afirmarse que tanto All that Jazz como la presencia en el cine y en Broadway de los grandes coreógrafos-directores como el propio Fosse, Jerome Robbins o el ya mencionado Michael Bennet, ayudo al cambio en la representación del coreógrafo en la pantalla que se ha visto anteriormente entre películas como The Red Shoes rodada en 1950 y posteriores como Black Shawn de 60 años después.

\section{Referencias bibliográficas}

Armada Manrique, Ignacio J. 2001. "La vida es un cabaret: Bob Fosse y el cine musical que no existe". Nickel Odeon 25: 92-100

Driver, lan. 2001. Un siglo de baile: Cien años de movimiento al son de la música. Traducido por Imma Guàrdia Rúbies Barcelona: Blume

Feuer, Jane. 1992. El musical de Hollywood. Traducción; Fuen F. Escribano \& Rafael R. Tranche. Madrid: Verdoux

Fosse, Bob. (1987) 2017. "Bob Fosse, Interview and Profile". By David Sheehan. Vídeo de Youtube, 6:40. www.youtube.com/watch? $\mathrm{v}=\mathrm{k} 18 \mathrm{~K} 3 \mathrm{ImcojE \&} \mathrm{t}=36 \mathrm{~s}$ 
McRobbie, Angela. 1997. "Dance Narratives and Fantasies of Achivements". En Meaning in motion: New cultural studies of dance, editado por Jane C. Desmond, 207-31. Durham NC: Duke University

Minguet, Joan María. 2013. "Más allá de la realidad: George Méliès y el primer cine de la fascinación". Conferencia presentada en Caixa Forum Madrid, 18 sept.

Moreno Candeal, Luisa. 2008. "Bailes de pareja en el cine musical de Hollywood”. Tesis Univ. Complutense de Madrid

Ramos, Rafael. 1987. "Bob Fosse: Acabó el espectáculo". La Vanguardia, 25 sept. http:// hemeroteca.lavanguardia.com/preview/1987/09/25/pagina-37/33000303/pdf.html?search=bob\%20fosse

Sánchez-Escalonilla, Antonio. 2002. Guión de aventura y forja del héroe. Barcelona: Ariel

Sheider, Roy. (1980) 2017. "Roy Sheider/Jaws/All That jazz". Entrevista por Eileen Prose. Vídeo de Youtube, 8:44. www.youtube.com/watch?v=qIQy95N_yyk\&t=228s

\section{Películas citadas}

Ardolino, Emile. 1988. Dirty Dancing. EEUU, MGM

Aronofsky, Darren. 2010. Black Swan (Cisne negro). EEUU, RSO Records

Attenborough, Richard. 1985. A Chorus Line. EEUU, Columbia Pictures

Baumbach, Noah. 2012. Frances Ha. EEUU, Scott Rudin Productions

Beresford, Bruce. 2009. Mao's Last Dancer (El último bailarín de Mao). Australia, Last Dancer Pty Ltd.

Bollaín, Icíar. 2018. Yuli. España, Morena Films

Daldry, Stephen. 2000. Billy Elliot. Reino Unido, BBC Films, Tiger Aspect Pictures \& Working Title Films

Di Giusto, Stéphanie. 2016. La danseuse (La bailarina). Francia, Productions du Tresor \& Wild Bunch

Fame Allan Parker. EEUU, MGM, 1980.

Fletchee, Anne. 2006. Step Up. EEUU, Summit Entertainment

Fosse, Bob. 1980. All That Jazz. EEUU, Columbia Picures \& Twentieth Century Fox

Hytner, Nicholas. 2000. Center Stage (El ritmo del éxito). EEUU, Columbia Picture Corporation

Koster, Henry. 1947. The Unfinished Dance (La danza inconclusa). EEUU, MGM

Lyne, Adrian. 1983. Flash Dance. EEUU, Paramount Pictures

Méliès, Georges 1903. Le reve du maitre de ballet. Francia, Star Film Company

Powell, Michael. 1950. The Red Shoes (Las zapatillas rojas). Reino Unido, The Archers

Sandrich, Mark. 1937. Shall we dance? (Ritmo loco). EEUU, RKO Pictures

(Artículo recibido: 08-10-19; aceptado: 21-10-19) 